\title{
HUMOR BERBAHASA MINANG DALAM MEME DI INSTAGRAM
}

\author{
Amelia Khairunnisa ${ }^{1 *}$, Pramono ${ }^{2}$, Yerri Satria Putra ${ }^{3}$ \\ ameliakhairunnisa619@gmail.com* \\ Fakultas Ilmu Budaya Universitas Andalas ${ }^{1,2,3}$
}

\begin{abstract}
ABSTRAK
Meme merupakan salah satu sarana dalam menyampaikan informasi, pendapat atau opini bahkan sebagai sindiran untuk suatu kebijakan. Hadirnya meme humor menjadi cara kreatif dalam menyuarakan fenomena-fenomena yang terjadi di masyarakat. Penelitian ini bertujuan untuk menjelaskan meme apa saja yang menampilkan humor berbahasa Minang di Instagram, serta bagaimana proses dan makna meme tersebut dalam perspektif analisis wacana kritis. Sampel yang digunakan dalam penelitian ini adalah seratus meme humor berbahasa Minang di media sosial Instagram. Hasilnya, sebuah meme humor lahir tidak terlepas dari kaitannya dengan 'teks' lain seperti komentar warganet, meme lainnya yang memiliki makna serupa dan fenomena sosial yang melatarbelakangi munculnya meme tersebut. Fenomena-fenomena tersebut berangkat dari berbagai isu yang terjadi seperti isu budaya, isu politik, isu pendidikan, isu sosial serta isu ekonomi.
\end{abstract}

Kata kunci: analisis wacana kritis, meme, humor, Instagram

\section{MINANGKABAU HUMOR IN INSTRAGRAM MEME}

\begin{abstract}
A meme is a means of conveying information, opinions, or opinions even as an insinuation for a policy. The presence of humorous memes is a creative way to express the phenomena that occur in society. This study aims to explain what memes display Minang humor on Instagram and how the process and meaning of these memes are in the perspective of critical discourse analysis. The sample used in this study was a hundred humorous memes in Minang language on Instagram social media. As a result, a meme is inseparable from its relation to other "texts" such as netizens' comments. Other memes with similar meanings and social phenomena are the background for the emergence of these memes. These phenomena depart from various issues, such as cultural issues, political issues, educational issues, social issues, and economic issues.
\end{abstract}

Keywords: critical discourse analysis, meme, humor, Instagram 


\section{PENGANTAR}

Di media sosial Instagram saat ini, muncul fenomena baru yang sedang ramai diperbincangkan di kalangan pengguna internet atau warganet (netizen) sebagai salah satu bentuk kreatif dalam menyebarkan informasi. Fenomena ini dikenal dengan istilah meme. Istilah meme pertama kali dikemukakan oleh Richard Dawkins (1976:189) yang merujuk pada unit imitasi dan transmisi budaya dalam gen. Menurutnya, meme adalah bentuk transmisi budaya melalui replikasi ide gagasan. Konsep inilah yang diaplikasikan dalam konteks fenomena sosial khususnya yang terjadi di internet.

Secara sederhana, meme dapat dipahami sebagai tulisan atau gambar (bisa gabungan keduanya) yang menjadi simbol atau lambang sebagai wujud dari hasil kreativitas maupun curahan hati yang disampaikan kepada khalayak. Meme menjadi entitas yang dihasilkan oleh budaya baru di internet. Dalam perkembangannya, selain untuk tujuan menghibur, meme dianggap dapat menjadi sarana dalam menyampaikan opini atau pendapat hingga senjata propaganda lewat sindiran dengan tujuan mengubah sikap atau pendapat orang lain.

Menurut Mahmud (1994: 1) humor merupakan salah satu sumber rasa gembira yang menyatu dengan kelahiran manusia. Humor memiliki peranan penting dalam kehidupan manusia. Humor dapat melepaskan manusia dari hal-hal yang menegangkan dan tidak menyenangkan. Setiap bangsa maupun etnis memiliki perspektif yang berbeda mengenai definisi humor ini. Humor menurut pandangan orang-orang timur akan berbeda dengan pandangan orang-orang barat. Sesuatu yang dianggap lucu oleh etnis Batak akan berbeda dengan yang dianggap lucu oleh etnis Minang. Hal ini dilatarbelakangi oleh lingkungan sosial masyarakatnya.

Hadirnya meme humor ini sebagai salah satu jawaban terhadap kebutuhan manusia sebagai makhluk yang spontan dan senang bermain-main. Kehadiran humor digunakan masyarakat untuk mencairkan suasana sehingga menimbulkan senyum dan tawa. Meme yang mengandung humor ini disajikan menggunakan teks singkat dan sederhana, tetapi mengandung logika yang tidak masuk akal dan membuat penikmat atau pembaca menjadi berpikir. Hal ini merupakan tuntutan dari konsumsi yang praktis. Meme menjadi cerminan bagi kenyataan sosial yang ada. Dengan kata lain, gambar yang terdapat dalam meme menuturkan sebuah representasi dari kehidupan bermasyarakat.

Berangkat dari latar belakang di atas, peneliti merumuskan masalah meme apa saja yang menampilkan humor berbahasa Minang di Instagram dan bagaimana proses dan makna meme tersebut dalam perspektif analisis wacana kritis.

\section{KERANGKA TEORI DAN METODE}

Dalam penelitian ini, penulis fokus mengkaji penggunaan meme dalam media sosial instagram sebagai sumber data dan kemudian menganalisis meme-meme yang berkaitan dengan humor. Sebagai batasan penelitian, penulis terfokus kepada satu tujuan penelitian untuk menjelaskan bagaimana humor yang digambarkan melalui memememe yang ada di media sosial Instagram. Penjelasan mengenai humor dalam meme tersebut menggunakan pendekatan analisis wacana kritis Norman Fairclough. 
Secara sederhana, analisis wacana dapat dipahami sebagai suatu bentuk dalam upaya pengungkapan makna atau maksud tersembunyi dari penghasil wacana yang mengemukakan suatu pernyataan. Sedangkan kritis sendiri fokus pada apa yang salah dari sebuah masyarakat (sebuah institusi, sebuah organisasi, dan lain-lain) dan bagaimana kesalahan-kesalahan tersebut dapat dikoreksi atau diminimalkan dari sudut pandang normatif tertentu (pada penelitian sosial normatif). Kritik ini didasarkan pada nilai-nilai, khususnya pandangan masyarakat yang baik dan kesejahteraan manusia serta perkembangannya, berdasarkan evaluasi masyarakat yang sudah ada dan cara yang mungkin untuk mengubahnya (Fairclough, 2010: 7).

Fairclough menyatakan bahwa "CDA is not analysis of discourse 'in itself' as one might take it to be, but analysis of dialectical relations between discourse and other objects, elements or moments, as well as analysis of the 'internal relations' of discourse. Jadi, analisis wacana kritis tidak hanya analisis wacana itu sendiri, melainkan juga merupakan analisis dari hubungan dialektik antara wacana dan objek, elemen atau momen lainnya, serta analisis 'hubungan internal wacana' (Fairclough, $2010: 4$ ).

Fairclough (1985) memberi penekanan terhadap wacana dari aspek bahasa dan juga dari aspek teks. Fairclough beranggapan bahwa analisis wacana kritis merupakan satu kaedah penggunaan bahasa yang digunakan oleh kelompok-kelompok tertentu untuk menjelaskan mengenai pandangan dan ideologi terhadap suatu masalah. Analisis ini juga bertujuan untuk melihat segi penggunaan bahasa dan juga tulisan sebagai praktik sosial yang akan memberikan keterkaitan terhadap suatu isu ataupun peristiwa yang berlaku, di samping menyampaikan ideologi individu atau kelompok.

Dalam penelitian ini, metode penelitian yang digunakan adalah penelitian analisis teks dengan mengaplikasikan pendekatan Critical Discourse Analysis (CDA) dari Norman Fairclough. Prinsip utama dalam pendekatan ini adalah teks hanya bisa dipahami jika dikaitkan dengan teks-teks lain dalam konteks sosial.

The method of discourse analysis includes linguistic description of the language text, interpretation of the relationship between the (productive and interpretative) discursive processes and the text, and explanation of the relationship between the discursive processes and the social processes (Fairclough, 1995: 97)

Dalam bukunya yang berjudul Critical Discourse Analysis: The Critical Study of Language (1995: 98), Fairclough membuat model analisis wacana kritis. Teks memiliki konteks baik yang berdasarkan pada proses produksi teks, proses interpretasi teks maupun praktik sosio- kulturalnya. Pada penelitian ini, meme humor berbahasa Minangkabau di media sosial Instagram tidak hanya dianalisis dari segi kebahasaan tetapi juga dihubungkan dengan konteks tujuan dan praktek kekuasaan yang tersirat di dalamnya.

Teknik pengumpulan data yang digunakan dalam penelitian ini dilakukan dengan menghimpun data meme berbahasa Minangkabau yang mengandung humor. Meme yang memiliki konten humor di dalamnya merupakan data primer dalam penelitian ini. Sedangkan untuk data sekundernya adalah komentar-komentar yang muncul setelah meme ini diunggah dalam sebuah akun di media sosial. Namun tidak semua meme Minang yang humor yang terdapat di Instagram akan diambil sebagai data. Hanya beberapa meme yang dipilih secara acak dan dapat mewakili meme yang lain sebagai representasi fenomena yang terjadi di masyarakat diambil sebagai data untuk penelitian ini. Untuk mendapatkan data-data tersebut, peneliti dapat menggunakan hashtag, diantaranya \#mememinang, \#urangminang, 
\#urangawak, \#urangpadang, \#minangbana, \#budayaminang, \#minanglawak. Hashtag tersebut dicari pada kolom pencarian di media sosial Instagram.

\section{HASIL DAN PEMBAHASAN}

Di media sosial saat ini, muncul fenomena meme yang sedang ramai diperbincangkan di kalangan pengguna internet (netizen) sebagai salah satu bentuk kreatif dalam menyebarkan informasi. Meme menjadi cerminan bagi kenyataan sosial yang ada. Dengan kata lain, gambar yang terdapat dalam meme menuturkan sebuah representasi dari kehidupan bermasyarakat. Salah satu bentuk kreatif tersebut adalah hadirnya meme yang bertemakan humor guna menghibur serta menjadi perwakilan bagi masyarakat untuk memahami kebudayaannya.

Hasil penelitian menunjukkan, ragam meme yang ditemukan berupa meme dengan tulisan, meme dengan tulisan dan gambar. Adapun pembahasannya sebagai berikut.

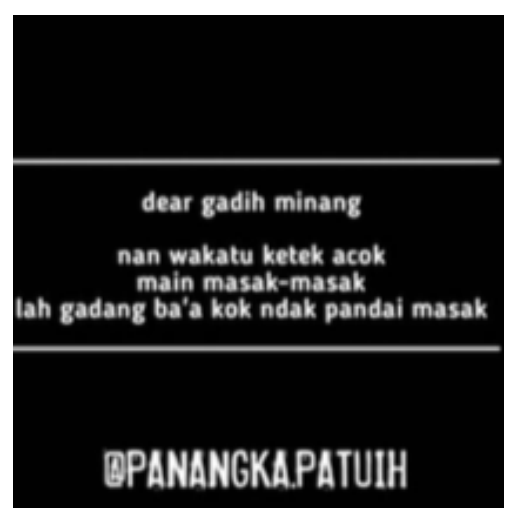

GAMBAR 1. Meme dear gadih.

Meme ini dear gadih minang nan wakatu ketek acok main masak-masak lah gadang ba'a kok ndak pandai masak, 'Dear gadih Minang, yang waktu kecil dulu sering main masak- masakan tapi kenapa sudah besar tidak pandai memasak' diunggah oleh akun @panangka_patuih dengan tanda suka sebanyak 120 likes. Meme yang diunggah pada tanggal 11 September 2019 ini, berisi tentang gadih Minang yang ketika kecil suka bermain masak-masakan namun ketika sudah besar tidak pandai memasak. Pengunggah meletakkan nama akunnya di bagian bawah meme dengan menggunakan huruf kapital berwarna putih dengan latar meme berwarna hitam.

Meme ini lahir karena adanya anggapan dari masyarakat baik yang di dalam Minang maupun di luar Minang bahwa gadih Minang pasti ahli dalam urusan memasak. Seperti yang telah diketahui bahwa Minangkabau adalah salah satu etnis yang dibanggakan kulinernya hingga mendapatkan penghargaan sebagai makanan terenak di dunia. Dilansir dari situs resmi CNN Indonesia, dalam berita tersebut dipaparkan bahwa dua ikon kuliner Tanah Air rendang dan nasi goreng didaulat sebagai makanan terenak di dunia nomor satu dan nomor dua versi CNN. Sebelumnya pada 2011, masakan asal Sumatera Barat itu juga pernah mendapat peringkat pertama sebagai makanan terenak di dunia (CNN Indonesia, 2017) 
Perempuan di Minangkabau sangat diandalkan tenaganya dalam mengolah masakan di dapur. Selain untuk kebutuhan sehari-hari, keahlian dalam memasak ini juga dibutuhkan ketika kaum kerabat sedang mengadakan acara perhelatan atau acara penting lainnya yang membutuhkan banyak sajian makanan. Bila tidak ikut serta bekerja di dapur, ia akan disindir sebagai perempuan yang tidak pandai masak (Navis, 1984: 217). Hal ini dikarenakan sebagai limpapeh rumah nan gadang yang kesehariannya banyak dilakukan di dalam rumah, maka memasak menjadi suatu pekerjaan rumah yang tidak berat untuk dilakukan. Keberadaan perempuan seperti bundo kanduang maupun saudari perempuan, menjadi pendukung untuk bisa ahli dalam urusan dapur.

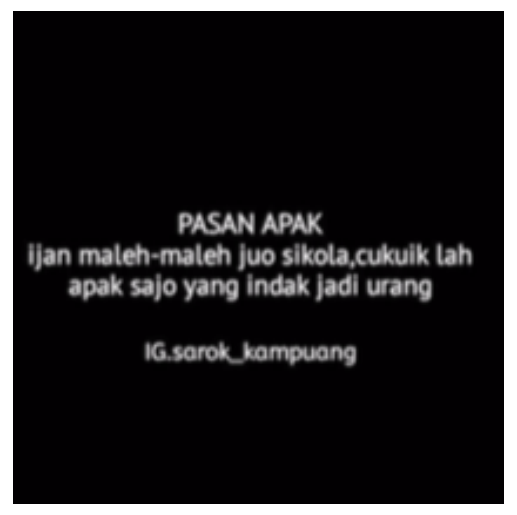

GAMBAR 2. Meme pasan apak.

Meme ini pasan apak ijan maleh-maleh juo sikola, cukuik lah apak sajo yang indak jadi urang, 'Pesan Ayah jangan malas ke sekolah, cukup Ayah saja yang tidak sukses' diunggah pada tanggal 11 September oleh akun @sarok_kampuang, dengan like pada meme sebanyak 476. Meme ini memiliki latar hitam polos dengan tulisan meme yang berwarna putih. Akun pengunggah diletakkan pada bagian bawah isi meme dengan warna tulisan yang sama dengan isi meme. Nasihat seperti itu disampaikan seorang Bapak kepada anaknya agar mengingatkan anak tersebut agar kelak ketika dewasa ia memiliki kehidupan yang baik dan tidak banyak menyusahkan orang lain. Karena tidak mungkin kesenangan di waktu tua tersebut akan dapat diraih jika sewaktu kecil malas untuk belajar.

Pendidikan adalah salah satu 'jembatan' dalam menggapai kesuksesan. Pendidikan menjadi jawaban bagaimana masa depan cemerlang itu akan mudah untuk diraih. Sekolah adalah salah satu sarana di mana pendidikan itu diajarkan. Di sekolah, sebuah sistem pendidikan diajarkan oleh guru kepada murid secara tersistem dengan baik. Banyak orang tua menginginkan anak- anak mereka bisa mengecap dunia pendidikan hingga ke perguruan tinggi. Harapannya, kelak dengan ilmu yang didapatkan tersebut dapat mengangkat derajat orang tua. Sehingga pesan atau nasehat dari orang tua kepada anak sering ditemui dalam kehidupan sehari-hari.

Di Minangkabau, selain sebagai tradisi turun temurun, merantau menjadi salah satu cara dalam memperbaiki kondisi finansial. Anak laki-laki yang dirasa sudah cukup bekal untuk pergi merantau akan dipersiapkan oleh orang tuanya untuk keluar dari kampung dan menggali ilmu yang banyak di tanah rantau. Dengan berbekal ilmu agama yang didapat dari surau dan ilmu bela diri yang didapat dari galanggang, maka anak tersebut akan merantau dengan dititipkan kepada sanak saudaranya yang berada di rantau atau dikenal dengan istilah induak samang. 
Wilayah rantau pada mulanya merupakan wilayah untuk mencari kekayaan secara individual oleh penduduk, baik dalam bidang perdagangan, usaha, dan jasa maupun dalam kegiatan lain yang sifatnya sementara (Navis, 1984: 107). Menurut Navis, merantau merupakan produk kebudayaan orang Minangkabau. Setiap orang, terutama anak muda akan senantiasa didorong dan ditarik agar pergi merantau oleh kaum kerabatnya dengan berbagai cara.

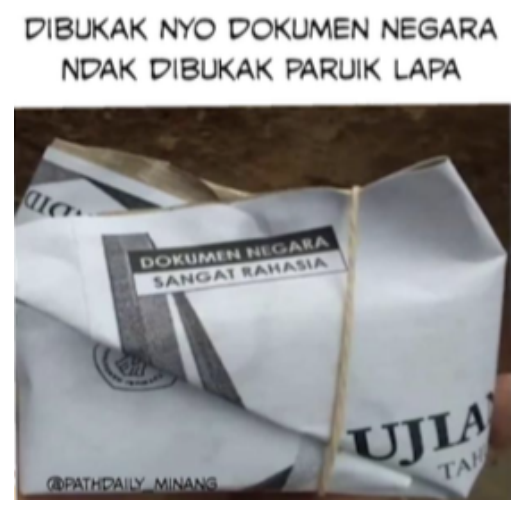

GAMBAR 3. Meme dokumen negara.

Meme ini dibukak nyo dokumen neegara ndak dibukak paruik lapa, 'Jika dibuka, ia adalah dokumen Negara, jika tidak dibuka perut menjadi lapar' diunggah oleh akun@pathdaily_minang pada tanggal 4 Januari 2020 dengan like pada meme sebanyak 5666 orang. Meme ini menggunakan gambar nasi bungkus sebagai latar pada meme humor ini. Dengan tulisan "Dokumen Negara, sangat rahasia" tersebut maka nasi bungkus tersebut tidak dapat dibuka sembarangan. Meme humor ini menjadi representasi dari fenomena yang terjadi di masyarakat bahwa kebiasaan penjual makanan yang sering menggunakan berbagai macam kertas untuk membungkus makanan tersebut. Ada penjual yang membungkus makanan dengan kertas koran, bekas buku pelajaran, hingga kertas soal Ujian Nasional seperti yang terdapat pada gambar meme tersebut.

Salah satu cara dalam penyajian makanan di Rumah Makan atau Ampera adalah dengan dibungkus. Kertas pembungkus yang digunakan bermacam-macam. Normalnya, pembungkus yang digunakan adalah kertas nasi yang berwarna cokelat. Namun tidak jarang kertas pembungkus yang digunakan adalah kertas yang fungsi utamanya bukan untuk membungkus makanan. Seperti yang terlihat pada gambar meme yang menggunakan kertas Ujian Nasional sebagai pembungkus makanan. Ujian nasional pada tingkat SMP dan SMA pada tahun 2018 masih diadakan dengan sistem ujian tulis. Dengan sistem ini, lembar soal akan diberikan untuk masing-masing peserta ujian. Pada saat ujian berakhir, para peserta ujian harus mengembalikan lembar jawaban beserta lembar soal ujian. Oleh karena itu, seharusnya dokumen ini hanya dimiliki oleh pihak tertentu. Maka tidak heran, jika dokumen ini disebut sebagai dokumen Negara dan sangat rahasia. Sehingga akan timbul pertanyaan dari netizen mengapa terdapat lembar soal Ujian Nasional yang dijadikan sebagai bahan pembungkus makanan. 


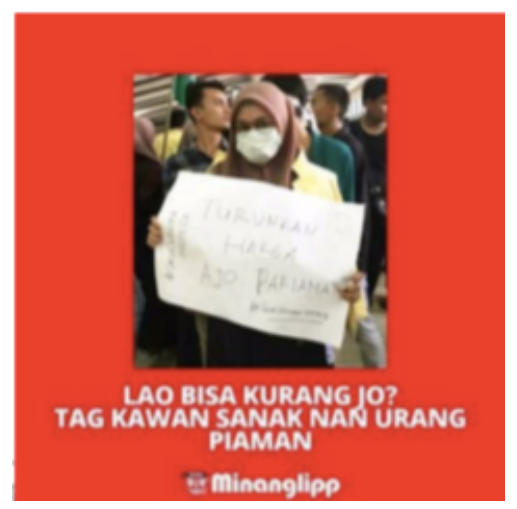

GAMBAR 4. Meme kato amak.

Meme humor ini diunggah oleh akun @minanglipp, pada tanggal 16 September 2019. Jumlah like pada meme ini sebanyak 5323 dan 444 komentar. Meme ini diunggah tepat satu hari setelah diadakan demo mahasiswa dari berbagai perguruan tinggi di Sumatera Barat yang bertempat di kantor DPRD (Dewan Perwakilan Rakyat Daerah) Sumbar. Dalam meme ini terlihat seorang mahasiswi yang tengah memegang sebuah kertas putih yang berisi tulisan Turunkan harga ajo pariaman. Pengunggah menambahkan pernyataan yang mendukung isi meme tersebut dengan pernyataan yang maknanya adalah bisa kurang (harga uang jemputan) jo (panggilan untuk laki-laki di pariaman)?. Pengunggah juga meletakkan nama akunnya di bagian bawah meme.

Meme ini diunggah di Instagram, sebagai salah satu aplikasi media sosial yang banyak diunduh oleh pengguna internet. Meme ini dibuat berangkat dari tradisi 'Uang jemputan' yang belum mendapat penerimaan baik di tengah masyarakat. Komentar pada sebuah unggahan merupakan salah satu cara berkomunikasi dalam media sosial. Dengan melihat berbagai komentar yang bermunculan, hal ini membuktikan bahwa pembahasan yang terdapat pada meme tersebut merupakan representasi dari fenomena yang terjadi. Seperti yang terlihat pada komentar di bawah ini yang berkaitan dengan meme yang diunggah oleh akun@piaman_lawak di atas.

Untuk mendukung tersampaikannya isi meme ini, pengunggah menambahkan kalimat pada bagian bawah gambar. Kalimat itu berbunyi "lao bisa kurang jo? Tag sanak kalian nan urang Piaman". Terdapat typing error (kesalahan penulisan) pada penulisan pernyataan tersebut. Pengunggah seharusnya menggunakan kata "lai" bukan kata "lao". Kalimat "tag sanak kalian nan urang Piaman" ini menjadi penegasan bahwa seharusnya semua laki-laki Pariaman harus mengetahui perihal polemik yang terjadi terhadap tradisi ini.

Aspirasi itu disampaikan mahasiswa dengan menggunakan poster. Uniknya, di mana pada umumnya setiap demonstrasi, mahasiswa akan menyampaikan aspirasi mengenai topik yang tengah dibahas. Namun, mahasiswi ini menggunakan poster yang bertuliskan 'Turunkan harga ajo piaman' dengan hashtag \#savewanitaindonesia dan hashtag \#savewanitaminang. Ini menjadi gambaran bahwa tradisi uang jemputan ini masih belum sepenuhnya mendapat penerimaan yang baik dari masyarakat. Hadirnya sosok mahasiswi di sini menandakan bahwa generasi muda masa kini menjadi salah satu korban dalam 'mahalnya' uang jemputan ini. Mahasiswi pada meme ini menggunakan hashtag \#savewanitaindonesia dan hashtag \#savewanitaminang sebagai bentuk bahwa kaum wanitalah 
yang butuh perhatian dalam hal ini. Dapat disimpulkan bahwa sasaran dari tuntutan mahasiswi tersebut bukanlah anggota Dewan, melainkan kepada orang Pariaman yang masih memegang teguh prinsip uang jemputan ini.

Seperti yang telah peneliti kemukakan, latar belakang dari hadirnya meme ini adalah karena adanya reaksi dari banyak pengguna internet khususnya etnis Minangkabau mengenai Tradisi uang jemputan yang ada di Pariaman. Uang jemputan ini adalah salah satu prosesi yang terdapat dalam perkawinan di Pariaman. Menurut Navis (1984: 197198), tata cara perkawinan dapat dibagi menjadi atas dua bagian, yakni: perkawinan menurut syarak (agama) dan perkawinan menurut adat Minangkabau. Menurut syarak artinya perkawinan tersebut didasarkan pada ajaran agama Islam dengan mengucapkan akad nikah di hadapan Kadhi. Minangkabau yang dikenal dengan adat istiadatnya memiliki kriteria tertentu untuk perkawinan. Perkawinan belum dirasa komplet jika tidak menghadirkan baralek (perhelatan) di dalamnya.

Di Pariaman, terdapat sebuah tradisi di mana pihak laki-laki diberi 'uang jemputan' oleh pihak perempuan. Kesepakatan mengenai berapa besar uang jemputan ini didasarkan pada status sosial dari pihak laki-laki. Jika lakilaki tersebut bekerja sebagai seorang petani maka akan berbeda uang jemputannya dengan laki-laki yang memiliki profesi sebagai seorang dokter. Kesepakatan mengenai uang jemputan ini dilakukan oleh mamak dari kedua belah pihak Navis dalam bukunya berjudul Alam Takambang Jadi Guru (1984: 200-201) memaparkan bahwa adat memberikan uang jemputan pada masa dahulu hampir merata dilaksanakan di seluruh Minangkabau. Nilainya sampai sekitar 50 gram emas murni. Jika pada masa lalu uang jemputan itu dilakukan bagi orang yang mempunyai darah bangsawan, maka kini telah bergeser kepada setiap pemuda penduduk asli yang mempunyai gelar kesarjanaan. Yang paling tinggi nilainya ialah para sarjana yang diharapkan akan banyak menghasilkan uang seperti dokter dan insinyur teknik. Besarnya uang jemputan bukan lagi dinilai dengan emas, melainkan kendaraan bermotor, paling rendah senilai sebuah sekuter.

Setelah dilakukan analisis terhadap seratus meme humor berdasarkan isu yang terdapat dalam konten memememe humor tersebut, maka terdapat beberapa makna dalam meme humor berbahasa Minang di media sosial Instagram tersebut, yaitu sebagai berikut.

a. Meme humor dapat dimaknai sebagai bentuk komunikasi era digital

Seperti yang telah dipaparkan sebelumnya bahwa era digital saat ini menuntut konsumsi yang praktis. Meme menjadi salah satu sarana dalam berkomunikasi yang termediasi oleh media sosial Instagram. Komunikasi tidak lagi dilakukan secara langsung atau tatap muka, melainkan ditansformasi dalam bentuk unggahan. Pembuat meme memulai komunikasi dengan mengunggah meme humor di akun Instagramnya, lalu komunikasi terjadi ketika warganet yang melihat unggahan tersebut memberikan tanda suka (like) atau meninggalkan komentar pada kolom komentar unggahan tersebut. Pada kolom komentar ini warganet dibebaskan untuk berkomentar juga dapat menandai akun lain pada kolom komentarnya.

Selain itu, pada kolom komentar juga terdapat akses bagi akun lainnya membalas komentar yang ada. Berdasarkan paparan di atas terlihat bahwa komunikasi pada era digital dengan menjadikan meme sebagai objek untuk 
berkomunikasi tersebut dapat dilakukan dengan praktis. Pembuat meme dan warganet yang menanggapi respon tersebut dapat berkomunikasi dengan mudah dan dapat dilakukan dimana saja.

b. Meme humor dapat dimaknai sebagai penyampai opini

Tidak jarang ditemui dalam beberapa unggahan meme berisi opini atau pendapat dari pembuat meme. Meme yang berisi opini atau pendapat tersebut biasanya diunggah berkaitan dengan suatu kebiasaan, tradisi hingga kebijakan pemerintah. Konten-konten yang berisi pendapat tersebut menghadirkan unsur humor di dalamnya. Hal ini tentu dikarenakan tujuan menghibur dari meme itu sendiri. Namun dapat dijumpai opini atau pendapat yang berisi humor tersebut berisi sindiran terhadap fenomena sosial yang melatarbelakanginya.

Dengan kehadiran meme humor ini, dapat menjadi sarana dengan nuansa 'baru' dalam menyampaikan opini atau pendapat. Opini atau pendapat yang dulunya hanya bisa disampaikan dalam forum-forum tertentu, kini dapat mudah ditemui dengan hanya mencari kata kunci pada kolom pencarian Instagram. Salah satu contohnya adalah ketika seseorang ini mengkritisi kebijakan yang dikeluarkan oleh pemerintah. Penggunaan media sosial, khususnya instagram yang masif ini menjadi sarana yang mendukung dalam menyampaikan opini tanpa harus ikut dalam forumforum yang diadakan oleh pemerintah. Pembuat meme dapat dengan mudah dan bebas menyampaikan opini atau pendapatnya melalui meme humor yang diunggah di akun Instagramnya. Meme tersebut juga bisa diunggah ulang oleh akun lainnya di Instagram sehingga informasi mengenai pendapat yang terdapat dalam meme tersebut akan mudah untuk diketahui oleh banyak orang.

c. Meme humor dapat dimaknai sebagai bentuk kreatif dalam menggunakan media sosial

Semakin berkembangnya teknologi informasi, semakin berkembang juga kreativitas yang dihasilkan. Salah satu bentuk kreativitas tersebut adalah kehadiran meme di media sosial. Terlihat dari meme-meme humor di setiap unggahan tersebut dihasilkan dari kreativitas pembuat meme. Terlihat dalam meme tersebut bagaimana kreativitas pembuat meme dalam memilih diksi (pilihan kata) yang tepat serta gambar yang dapat mendukung tersampaikannya maksud dan humor dalam meme tersebut.

Pembuat meme harus melakukan riset terlebih dahulu sebelum memutuskan untuk membuat meme dengan konten humor di dalamnya. Pembuat meme harus 'membaca' peristiwa apa sedang hangat diperbincangkan dan banyak menuai perhatian serta berbagai respons atau tanggapan dari publik. Untuk meme berbahasa Minang, pembuat meme berkreasi dengan pilihan penggunaan bahasa Minang yang digunakan. Hal ini dikarenakan setiap daerah memiliki dialeknya masing-masing.

d. Meme humor dapat dimaknai sebagai identitas dari suatu kelompok masyarakat

Berbagai meme humor berbahasa daerah dapat ditemui dalam berbagai akun di media sosial Instagram. Meme-meme humor berbahasa daerah tersebut dibuat sebagai bentuk eksistensi dari setiap etnis yang bersangkutan. Penelitian yang menjadikan meme humor berbahasa Minang sebagai objek penelitian ini menggambarkan eksistensi orang Minang yang ikut mengkritisi berbagai fenomena yang terjadi di masyarakat. Fenomena-fenomena tersebut berangkat dari berbagai isu yang terjadi. Mulai dari isu budaya, isu pendidikan, isu politik, isu sosial serta isu ekonomi. Hal ini menandakan bahwa orang Minang tidak luput dalam menanggapi berbagai fenomena yang terjadi melalui 
media sosial Instagram. Meme berbahasa Minangkabau menjadi salah satu sarana dalam menjaga eksistensi bahasa Minangkabau serta menjadi representasi mengenai aktivitas sosio budaya Minangkabau yang ada.

\section{PENUTUP}

Di era media sosial saat ini, meme menjadi salah satu saran dalam menyampaikan informasi, pendapat atau opini, bahkan sebagai sindiran untuk suatu kebijakan. Hadirnya meme humor menjadi cara kreatif dalam menyuarakan fenomena-fenomena yang terjadi di masyarakat. Selain dalam bahasa nasional, meme juga dapat ditemui dalam bahasa daerah, salah satunya adalah bahasa Minangkabau.

Dalam penelitian ini, meme humor berbahasa Minangkabau diambil dari beberapa akun di media sosial Instagram. Meme humor tersebut dianalisis dengan menggunakan pendekatan analisis wacana kritis yang meliputi analisis teks, analisis proses dan analisis sosial. Hasilnya, sebuah meme humor lahir tidak terlepas dari kaitannya dengan 'teks' lain seperti komentar warganet, meme lainnya yang memiliki makna serupa dan fenomena sosial yang melatarbelakangi munculnya meme tersebut.

\section{REFERENSI}

Anuar, F. N., Ahmad, F., \& Salleh, S. M. (2018). Meme sebagai seloka persendaan dan parodi: Impak dimensi sosiobudaya. Jurnal Komunikasi: Malaysian Journal of Communication, 34(1). Retrieved fromhttp://ejournals.ukm.my/mjc/article/view/22004

BeritaSatu.com. (2020, Juny 3). "Jalan Panjang RUU KUHP”. Retrived from https://www.beritasatu.com/fokus/jalan-panjang-ruu-kuhp

Budiwiyanto, Adi. Kontribusi kosa kata bahasa daerah dalam bahasa Indonesia. Retrieved from http://badanbahasa.kemdikbud.go.id/lamanbahasa/content/kontribusikosakata-bahasa-daerah-dalam-bahasaindonesia\#

Brunello, J. (2012). Internet, memes andeveryday-creativity: agency socialability and the aesthetic of postmodernisme. Thesis. University of California, Los Angeles, United Statedof America

CNN Indonesia. (2020, July 3). Rendang \& Nasi Goreng dipilih Jadi Makanan Terenak di Dunia”. Retrived from https:/www.cnnindonesia.com/gaya-hidup/20170715172743-307-228130/ rendang-nasi-goreng-dipilih-jadimakanan-terenak-di-dunia

Darma, Yoce Aliah. (2009). Analisis Wacana Kritis. Bandung: CV Yrama Widya Dawkins, R. (1976).

Fairclough, Norman. (1995). Kesadaran Bahasa Kritis. Terjemahan Hartoyo. IKIP Semarang Press: Semarang. 375 hal.

Fairclough, Norman. (1995). Critical Discourse Analysis: The Critical Study of Language. Singapore. Longman Singapore Publishers (Pte) Ltd

Fairclough, Norman. (2010). Critical Discourse Analysis: The Critical Study of Language. (Second Edition). London: Pearson Education Limited

Hidayat, H. N., Wasana, Pramono, Immerry, T., \& Dahlan, F. (2019). Folklore in Meme: Minangkabau Folklore Survival Form in The Digital World. Proceeding of INCOLWIS 2019. Padang. https://doi.org/10.4108/eai.298-2019.2288953

Hasanuddin.(2018). Wacana Etnik dalam Multikulturalisme Indonesia.Padang: Erka

Ida, Rahmah. (2014). Metode Penelitian Studi Media dan Kajian Budaya. Jakarta: Prenada Media Grup

Luxemburg, dkk.(1982). Pengantar Ilmu Sastra. Jakarta: Gramedia

Mahmud. (1994). Humor di dalam Sastra Klasik Sulawesi Selatan. Jakarta: Pusat Pembinaan dan Pngembangan Bahasa, Departemen Pendidikan Kebudayaan.

Merdeka.com. (2020, June 27). "Merana Jadi Lulusan SMA Jalur Corona". Retrived from https://www.merdeka.com/khas/merana-jadi-lulusan-sma-jalur-corona.html

Nasrullah, R. (2012). Komunikasi Antar Budaya di Era Budaya Siber. Jakarta: PrenadaMedia 
Navis, A.A. (1984). Alam Takambang Jadi Guru. Jakarta: PT. Temprint

Oktavianus. (2009). Analisis Wacana Lintas Bahasa. Padang: Andalas University

Omar, H. C. (2012). Analisis Wacana Kritis dalam Program Televisyen Raja Lawak dan Implikasinya Terhadap Psikososial Audiens di Malaysia. Jurnal Bahasa, 20(1),60-86.

Sugiyono.(2012). Metode Penelitian Kuantitatif Kualitatif dan R\&D. Bandung: Alfabeta.

Wasana, Hidayat, H. N., Immerry, T., Dahlan, F., Pramono, Meigalia, E., \& Sari, M. N. (2019). Pepatah Petitih: Its Interpretation On Instagram. Proceeding of INCOLWIS 2019. Padang. https://doi.org/10.4108/eai.29-82019.2289025 